\title{
Paradigm of Foreign Language Teaching and Learning: A Perspective of Self-Regulated Learning Environment Construction
}

\author{
Wei Zhao ${ }^{1,2}$ \\ ${ }^{1}$ College of International Studies of Southwest University, Chongqing, China \\ ${ }^{2}$ School of Foreign Languages of Dali University, Dali, China \\ Email:weizhao0806@yahoo.com
}

Received 18 September 2015; accepted 27 November 2015; published 26 May 2016

Copyright (C) 2016 by author and Scientific Research Publishing Inc.

This work is licensed under the Creative Commons Attribution International License (CC BY).

http://creativecommons.org/licenses/by/4.0/

c) (i) Open Access

\begin{abstract}
In the context of foreign language classroom teaching, this study provides a specific overview of the self-regulated learning and language learning strategies as well as other relevant concepts and theories. The analysis focuses on guiding foreign language teachers in helping students to implement self-regulated learning strategies and motivations, adjust to their learning experience, and respond to the teaching process through the interest adjustment, then build self-regulated learning environment from a theoretical approach, expectations for enlightenment to the practices in foreign language teaching and learning. The construction of self-regulated learning environment based on foreign language classroom, represents a perspective for language teachers and learners, which is a new direction of foreign language education and has not been articulated hitherto.
\end{abstract}

\section{Keywords}

Self-Regulated Learning, Learning Environment, Foreign Language Classroom, Teaching Paradigm

\section{Introduction}

For the purposes of this study, foreign language teaching can be characterized as any deliberate endeavor to promote foreign language learning by manipulating the components and mechanisms of learning and/or the conditions under which these operate. This deliberately broad definition covers an extensive variety of pedagogic and instructional approaches, methods, strategies, techniques, practices, and activities, all of which can be applied in an extensive variety of settings, although most typically in a foreign language classroom setting. Learning involves a change to the status quo, to what as of now exists. This means that the same learning object is 
likely to have different effects on different learners and different occasions of the same learners. These components with various emphases given to them and distinctive qualities attached to them are the premise for a progression of learning models: assessment for learning, observation, training, objective clarification, mentoring, peer-learning, simulation, instruction, concept-formation, reflection, meta-intellectual learning, critical thinking, problem-solving, and practice. These models give different emphases to the various elements of a learning environment in foreign language education context. Theoretical and contextual considerations impact, then, the study makes an exploration on how these components of teaching and learning are harmoniously realised.

Strategies for the foreign language classroom are situated at the interface of motivation research and classroom practice. They can be defined as instructional interventions consciously applied by foreign language teachers to elicit, enhance, and sustain student's motivated behavior, as well as protect it from competing (and thus potentially distracting) action tendencies [1]. No single strategy can always motivate every learner in any situation because of the dynamic character of the classroom context. The effectiveness of a strategy is the result of the interaction between constellations of contextual variables; some of them are probably culture-specific, and others are culture-neutral. Such variables include approaches to learning and teaching, educational ideology, individual learners and teachers' personality traits and emotional states, as well as the composition of the learner group [2]. Different learning environments may either enhance or neutralize the effectiveness of some strategies, but research is needed into the specifications of these learning environments.

A great deal of work remained to be done in terms of submitting these recommended strategies to empirical testing, even though this line of inquiry was initiated in 1998 by Dörnyei and Csizer. Dörnyei and Csizer's study of the motivational beliefs and practices of several teachers of English were valuable [3]. Yet, almost fifteen years on, relatively few empirical studies have been published in that vein, with most of them appearing very recently [4]. In spite of these efforts, much work remains to be done on the transferability of strategies to other cultural and ethno-linguistic contexts. This type of researches is essential if researchers are to make reasonable suggestions to educators regarding the design of motivating language learning environments. The value of self-regulated learning is in its emphasis on the individual as a pivotal agent in defining learning goals and strategies, and recognizing the issue as how that individual's perceptions of himself or herself, accompany with learning-task characteristics, to influence the quality of language teaching and learning. Thus, this study attempts to construct a self-regulated learning environment based on foreign language classroom setting, which represents a new teaching paradigm for language teachers and learners.

\section{The Concept of Self-Regulated Learning and Language Learning Strategies}

Self-regulated learning (SRL for short, similarly hereinafter) is an important research subject in the field of educational research. The concept of SRL is a relatively new area of educational research. It was developed in the 1980s, due to the profound changes of educational psychology, and received widely extensive concern by 1990s [5]. SRL refers to the process for learners taking the initiative to adjust the cognition, emotion and behavior, including cognition, behavior and motivation in order to enhance the learning effect and achieve learning goals, which includes elements of cognitive, behavioral and motivation in three areas [6]. The dimensions of SRL include dimension to learning motivation, learning method, learning time management, behavior operating, physical environment and social environment. Self-regulated learning subsumes key aspects of the learning process, such as cognitive strategies, meta-cognition and motivation in one coherent construct.

Language learning strategies can be defined as goal-oriented action, but generally not mandatory. That is to say, not only have the one way or right strategy to help learners achieve their goals. Since the action of the individual itself is constantly changing, sometimes it is possible to change the physical environment, and thus choose plans and strategies, along with the need for continuous adjustment. The function of adjusting strategy is different from person to person, not necessarily to any individual to exert its best features, of course, almost does not exist to the same individual learning strategies for all learning tasks and projects will be effective. Learning strategies should also be "adjust measures to actual conditions", according to the actual situation, the individual characteristics and specific tasks involved to select the corresponding strategies. In essence, SRL needs to coordinate the relationship between learning environment, learner characteristics and learning performance.

Self-regulated learners often have learning strategies, and have the inherent characteristics of motivation under the guidance of meta-cognitive theory. They are more likely to have a good performance in the classroom than other normal students, and even the former are more excellent than the latter in academic performance. Successful self-regulated learners were expected to have the capacity to perceive a need to learn; settle on wise 
decisions in connection to that need (about what to learn; how and when to learn it; and whom to learn in it with and from); and fulfill that need efficiently and reasonably (for instance, by getting information from the experiences of other different learners, then utilizing that information to set and accomplish their own learning objectives). What's more, since learning is effortful, self-regulated learners must have the capacity to sustain their motivation until their task is finished.

SRL strategies include cognitive strategies, meta-cognitive strategies and motivational monitoring strategies. On the cognitive level, the individual needs of the specific operation and practice; and in the meta-cognitive level, specifically how to use individual policies in a given area according to ability, background, and mission requirements. Self-regulated learning is usually a "three-stage" cycle process, which includes planning, implementation and self-reflection [7]. Learners in the planning stage are mainly analyzing the main tasks and personal motivation, which is also a strategic planning process. In addition, to master a skill or successful completion of a task, learners need to choose the reasonable method of tasks and situations or strategies.

The way that language learners need to monitor and control their learning activities has been described utilizing a number of different concepts. SRL as clarified above is one essential one, yet there exist various related concepts: meta-cognition, self-directed learning, self-organized learning, personalized learning and self-regulated personalized learning. In addition, to bring a self-regulated learning model into life in classrooms, teachers must be capable of exhibiting utilization of different self-regulated learning techniques, demonstrating the effectiveness of self-regulatory techniques in effective ways that students will comprehend and acknowledge, keeping records of students' progress, anticipating students' inquiries in regards to self-regulated learning, planning for the integration of self-regulated processes inside the educational programs, and refining their own planning and teaching methods in light of their experience with self-regulation training. Accordingly, we ought to consider each of these essential capabilities of teachers who have effectively implemented self-regulatory training into the curriculum of their classes [8].

\section{The Models of Self-Regulated Learning Theories in Foreign Language Teaching}

Theories of learning have been developed under three different paradigms: the behaviourist, the cognitive and the constructivist paradigm. While under the behaviourist paradigm, learning was defined as a change of behaviour due to external stimuli, the cognitivist paradigm essentially argued that the "black box" of the mind should be opened and understood. The model of the learner was not of a recipient of knowledge but an information processor. While constructivist agreeing that learning is related to knowledge about the world stress the fact that this knowledge is constructed by the individual in a social context [9]. SRL theory claims that students or learners are the subject of learning, and learning is a voluntary action of individual students. In the teaching process, only to fully mobilize the students' cognitive, emotional, behavioral, physiological and many other factors involved, in order to give full play to the initiative of students, promoting active exploration and development, forming positive in self-efficacy. SRL including thoughts, feelings, strategies and plans in advance and continually adjust a series of actions, and ultimately set their own learning goals [8]. Self-regulated learning ability does not increase with age and natural development. Therefore, students need a lot of supports based on selfregulated learning environment, in order to be gradually mature and become successful self-regulated learners. Self-regulated learning emphasizes the interdependence affect of objectives, content, process and evaluation between the four elements, thus focusing on regulation of student relations and interaction between these elements. Action, environment and the individual interacted with these actions, among them, the behavior and environmental influence each other.

The use of languages in foreign languages teaching is indispensable. Vygotsky (1896-1934) believes that language can be used as a tool in the process of learning. He took the universal inheritance law of cultural development as a starting point, claiming that language is a social media between people. Language, this tool was used for dialogue between the interlocutors. He then defined the language as of self-centered conversation, and the dialogue with oneself is actually for one's own guidance. He also believes that language is part of thinking, exists in the inner dialogue or verbal expression. Similarly, the self-regulating process originated from the social groups, is a process that learners gradually internalize, thus becoming part of the learners' personal skills. Thus, self-regulated learning occurs in specific social situations, for instance, in foreign language class. In addition, to understand how to use learning strategies, learners can also need to be clear when and where the use of these strategies. In other words, students must timely acquire the appropriate adjustment and control of learning.

The subjectivity of language learners is also an important factor in SRL. The language learner is the main 
body of actively participated in the language learning process and control the learning process, self-regulated learners learning behavior not only in the knowledge and skills of learning, but also in behavior, the formation of personality traits. In the process of students' self-regulated learning, teachers should pay attention to cultivating students' resolution quality, mobilize students' enthusiasm and initiative, cultivate students' self-monitoring and meta-cognitive abilities. Students in the language learning process should set goals and plans in the process of learning, and during the learning process, the students need self-monitoring and timely evaluation inconstantly adjusting strategies, in order to achieve the optimal learning effect [10].

According to Zimmerman, self-regulation of learning is a fundamental element for all academic enterprise and success. Self-regulated learners engage in actions, thoughts, and behaviors so as to pursue determined tasks. They do so by identifying goals and strategies and by monitoring and evaluating them [11]. Indeed, SRL has often been used synonymously with concepts such as self-management, self-control, action control, volition, self-change, self-directed behavior, coping behavior, and even meta-cognition and problem solving. Learning is viewed as knowledge acquisition through cognitive possessing of information, acquired both from being a part of society and from individual thought processes. Students' perceptions of the social environment (classroom environment) and their personal cognitive factors (self-regulated cognitions and self-regulated motivations) are hypothesized to affect the extent and nature of their behavior (self-regulated learning strategies) employed in an academic setting. Yet, although there are many fuzzy boundaries and distinctions, as well as numerous unresolved issues ranging from the conceptual to the methodological, scholars appear to be keen to invest energy in researching the topic because the stakes have been raised considerably since the time when the target of research was learning strategies only. To clear the concepts, the typical models of SRL theories can be summarized in "Table 1".

Table 1. Typical Models of principal theories of SRL.

\begin{tabular}{|c|c|c|}
\hline Reference & Characteristic & Description \\
\hline $\begin{array}{l}\text { Winne and } \\
\text { Perry(2000) [12] }\end{array}$ & $\begin{array}{l}\text { Effective strategy } \\
\text { employment }\end{array}$ & $\begin{array}{l}\text { SRL displays properties of an aptitude, which comprises two main dimensions, } \\
\text { metacognitive knowledge and metacognitive monitoring. }\end{array}$ \\
\hline \multirow{7}{*}{$\begin{array}{l}\text { Zimmerman and } \\
\text { Schunk (2001) [7] }\end{array}$} & Operant & Operant theories explore the ways in which delayed gratification can regulate learning. \\
\hline & Phenomenological & $\begin{array}{l}\text { These theories regard self-regulated learning in terms of self-identities and how they } \\
\text { affect the shaping of goals and approaches to learning. }\end{array}$ \\
\hline & Information processing & $\begin{array}{l}\text { Information-processing theories describe self-regulation in terms of feedback loops and } \\
\text { self-monitoring. }\end{array}$ \\
\hline & Social cognitive & $\begin{array}{l}\text { These theories consider self-regulation in connection to goal setting, expectancies, and } \\
\text { self-efficacy. }\end{array}$ \\
\hline & Volitional & $\begin{array}{l}\text { Volitional theories see self-regulation in terms persistence and maintaining attention in } \\
\text { the face of distractions. }\end{array}$ \\
\hline & Vygotskian & Vygotskian theories view self-regulation through the lens of sociocultural theory. \\
\hline & Constructivist & $\begin{array}{l}\text { These theories construe self-regulation as a function of the various strategies and } \\
\text { theories learners construct in order to tackle learning challenges. }\end{array}$ \\
\hline \multirow[t]{3}{*}{$\begin{array}{l}\text { Zimmerman and } \\
\text { Tsikalas (2005) } \\
{[13]}\end{array}$} & Cyclical process & $\begin{array}{l}\text { SRL as a cyclical process with three phases: } \\
\text { 1) The forethought phase: self-regulated students engage in metacognitive processes } \\
\text { (i.e., task analysis, goal setting, and strategic planning) and self-motivational processes } \\
\text { (task interest, values, intrinsic interest, self-efficacy). }\end{array}$ \\
\hline & & $\begin{array}{l}\text { 2) The performance phase: engage in metacognitive strategies (e.g., self-instruction, } \\
\text { attention focusing), behavioral strategies, metacognitive monitoring and behavioral } \\
\text { recording. }\end{array}$ \\
\hline & & $\begin{array}{l}\text { 3) The self-reflection phase: reflect upon and react to their performance (e.g., causal } \\
\text { attributions for success; feelings of satisfaction). }\end{array}$ \\
\hline \multirow{4}{*}{$\begin{array}{l}\text { Steffens (2006) } \\
{[14]}\end{array}$} & Regulating cognitive, & SRL involves three steps: \\
\hline & Motivational strategies, & $\begin{array}{l}\text { 1) Planning (including goal setting, assessment of internal and external resources and } \\
\text { selection of appropriate strategies). }\end{array}$ \\
\hline & $\begin{array}{l}\text { Domain-specific } \\
\text { knowledge, }\end{array}$ & $\begin{array}{l}\text { 2) Execution and monitoring (implementation of strategies, monitoring their success, } \\
\text { possibly choosing a different strategy). }\end{array}$ \\
\hline & $\begin{array}{l}\text { Specific learning } \\
\text { environments }\end{array}$ & 3) Evaluation (of the learning outcome). \\
\hline
\end{tabular}




\section{Teachers' Function in Self-Regulated Learning of Foreign Language Classroom Setting}

In previous studies of self-regulated learning, researchers pay more attention to the students, and less attention to the role of teachers [15]. Numerous studies indicate that the use of SRL strategies and student achievement is significantly correlated. From this perspective, through the teaching and training of self-regulated learning ability is helpful to improve the academic achievement. Beyond that, studies have found that self-regulated learning process can be taught, and can lead to students' motivation enhancement and performance improvement. How will teaching methods research into real classroom practice of this issue, resulting in the researchers realized that the teachers as an important decision-makers in the context of teaching situation, plays an indispensable role in the implementation of education reform and innovation of teaching [16]. Training students to learn self-regulated learning skills, it largely depends on the ability of teachers, enthusiasm and opinions and so on. Although teachers cannot be an expert level of understanding and skills directly entered into the students, but they can provide students with a variety of strategies of self-regulation, and to show them how to monitor the process of learning, and how a positive attitude towards learning outcomes to help students find themselves learning the most useful content.

The foreign languages classroom teaching based on self-regulated learning, for teachers and students, it represents a new teaching and learning paradigm. Developing a self-regulatory level of study skills with students depends greatly on the capabilities, enthusiasm, and perspectives of their teachers. To a certain extent, the implementation of its success does not lie in the effectiveness of psychological sense, but on whether teachers are willing to accept or not, and has made major changes in teaching methodology. In the self-regulated learning environment, teachers are the "leaders" of learning, to have a clear understanding for the students' evaluation. In the process of teachers guiding students in self-regulated learning, teachers need to personally participate in planning, monitoring, reflection, and try to constantly revise practice. Some researchers found that only if teachers themselves become self-regulated learners, show enough enthusiasm in learning different subject matter, rational use of teaching strategies to deal with complexity and difficulties in the process of classroom teaching, to show students a clear demonstration of methods and processes to solve the problem, in order to effectively help students become self-regulated learners. In the teaching process, teachers should also be combined with the contents of the teaching, and depending on the situations of the students, organized students to learn the knowledge content of conceptual understanding, and on the basic principles, basic methods, and the basic process and actively communicate with students.

Language teaching is the process of sharing their ideas and thoughts and the dialogue with each other, between teachers and students, between students and students and share their ideas and thoughts in this process. In the foreign language classroom teaching, teachers should create opportunities as much as possible for students through self-display, explore and discover the construction of individual knowledge. To design the structure of teaching, all the students can participate for the purpose of the use of learning materials and equipment, and have the opportunity to interact with teachers and peers. Training students to learn self-adjustment ability, but also must be based on the learning of the previous discussion of self-adjustment mechanism and the comprehensiveness, as well as training students in cognition, motivation, behavior, and context plans, monitoring, control and reflection ability, especially on goal setting and self-efficacy, meta-cognition, attribution and other aspects of training, and not just for students to increase self-study time or task. Teachers guide students to absorb new knowledge through guiding students to communicate with each other, fostering collaborative team spirit, offer better access to knowledge and ability to language problem-solving.

Taking the task interest in foreign classroom teaching and learning as an example, teachers hope that the classroom learning task for the majority of the students should be interesting, but the fact is that true? And how the students could treat the interest degree of their classroom activities? When students are tired of classroom activities, how to deal with this phenomenon? In this case, the student needs to talk to their teachers. Boredom is the antithesis of interest. Boredom refers to an unpleasant experience state caused in monotonous long-term stimulation, wherein disgust a single element of and have needs want to escape. If an activity task is interesting, people tend to want to do it. In contrast, when a task uninteresting, people are reluctant to participate or even abandoned. However, in this case, teachers should help students to stimulate interest in the use of self-regulation strategies to enhance students' motivation to complete the task, this strategy is called "make the task even closer to the students or make students feel pleasure", as one of the regulation strategies, and the specific approach is: 
take full advantage of the role of external motivation to mobilize the enthusiasm of students learning foreign language. The teachers themselves are one of the important sources of external motivation effect, through the cultivation of students' intrinsic interest in learning foreign language, to mobilize the enthusiasm of students. Interest can be divided into direct and indirect interest. Direct interest is, in itself, the interest caused by direct teaching activities, which would require teachers to make relatively boring material presented in the lively form, so that students feel interested in, so as to attract their attention. Indirect interest is interested in the results of learning activities. This is to make students come to understand that learning is hard, but the completion of their studies has an important role to their future study and work, to benefit from the infinite. To arouse the students' interest in foreign language learning task, the accepting ability differences of the students should be considered, for different objects, put forward appropriate requirements, so that each student can achieve their learning objectives [17].

\section{The Definitions and Features of the Field of Language Learning Environment}

Innovation and change in foreign language education has been a subject of interest for both teachers and researchers since the early days of foreign language teaching. Within the field of learning environments, at least six lines of research have been delineated by Fraser [18] [19], these being: 1) associations between student outcomes and environment; 2) evaluations of educational innovations; 3) differences between student and teacher perceptions of actual and preferred environments; 4) determinants of classroom environment; 5) use of qualitative research methods and; 6) cross-national studies. Of relevance to this study was research related to the use of student perceptual measures to guide improvements in the learning environment. The focus on classroom learning environments has been influenced by social cognitive theory, most prominently by Bandura, Vygotsky, Piaget and Bruner, which has seen the emergence of constructivist learning methodologies and the desire to create optimal learning environments which use stimulating materials and learning activities to guide, motivate and support student learning [20] [21]. Since foreign language learning is extremely popular throughout the world, developing modern assisted-learning environments that facilitate effective language learning is a critical issue in foreign language education. The situational learning approach' proposed that "context" (fundamentally in accordance with "environment”) is an important factor in foreign language learning, capable of enhancing learning interest and efficiency of the learners. Meaningful knowledge is constructed only when process of learning integrates with cultural and life contexts. Assimilating knowledge in a real world environment shortens learning time and enhances learning efficiency [22].

As indicated by the above theory, the study will explore the constructivist learning environment in specific foreign language teaching and learning context. Constructivist learning environments are frequently characterized by innovation or technology based spaces in which students 'explore, experiment, construct, converse and reflect on what they are doing so that they learn from their experiences'. A foreign education system is a unique combination of pedagogical, social and technological components. It is critical to distinguish a language learning environment from other subject circles or networked communities. The pedagogical component primarily reflects the educational purposes of a language learning environment. The pedagogical concept of a constructivist learning environment must enable students to construct knowledge and hence achieve learning objectives. In terms of constructivist learning theories, knowledge is actively constructed by learners based on their prior experiences, rather than specifically conveyed by the teacher. Moreover, cognitive constructivists claim that learners are most likely to construct knowledge individually dependent on their personal experiences and newly obtained information. In contrast to cognitive constructivism, social constructivists argue that knowledge is the outcome of collaborative construction in a social-cultural context mediated by discourse. Learning is a social process in which learners collaboratively construct knowledge through interactive processes of information sharing, negotiation and modification. In order to promote social knowledge construction, a language learning environment must provide a variety of communication situations or tools, such as synchronous (chat rooms and video conferencing) or asynchronous (discussion forums and online discussion) facilities. Such as a web-based learning environment certainly involves a technological element, as the majority of learning activities are conducted through the medium of the computer. Availability of and easy access to a learning environment are initial requirements, as an effective web-based learning environment must support anytime, anywhere learning [23].

A foreign language "learning environment" may have numerous implications: cultural, physical, mental, social, pedagogical, and technological or virtual. There are additionally physical learning environments, involving 
architectural designs, equipment, premises, and libraries, in addition to game, arts, science and wellbeing facilities, and materials. Also, there are mental learning environments, made out of human interaction in school and university, at work, or in the group. There are likewise social learning environments, including collaboration, cooperation, integration, and incorporation. Moreover, "learning environment" or a "powerful learning environment "may likewise apply to more concrete instructional or intellectual implications (constructivism, selfassessments, tutoring, and joint effort), in which case the epistemology of learning environments is less diffused and refers to classroom-specific, subject-specific, instruction-specific or technology-specific arrangements or interventions [24].

A defining feature of previous language learning environments research is that it has aimed to provide a means of obtaining students' perceptions of their classroom and its functionality in their learning. This study has focused largely on investigating the predictive ability of students' cognitive and attitudinal outcomes based on students' perceptions of the classroom learning environment. The other defining feature of learning environments research has been the emergence of a variety of approaches and methods ranging from those described as purely quantitative or qualitative and more recently those which combine quantitative and qualitative methods [25]. This study concentrated on the observation and events of classroom happenings. While early educational research focused on classroom variables such as ability and achievement, the focus has since shifted towards an investigation of other variables which influence student academic outcomes.

In the specific context of this study, it is important to note that learning environments vary in the degree to which students need to be self-regulated with a specific end goal to be successful. Supposing a learning environment is profoundly structured, engaging, and concentrated on the acquisition of a basic aptitude or task, students need not be self-regulated in order to be successful in that environment. Conversely, self-regulation is particularly required when: a) the environment is focused on complex, multi-step tasks in which possible solution strategies and results are not known ahead of time (so the learner must plan and monitor performance); b) it is possible for the learner to become distracted, lose interest, or forget the main objectives of the task; c) the task requires the use of strategies (e.g., note-taking) to defeat the processing limitations of the mind; d) learners must take part in supportive behaviors (e.g., planning, monitoring, strategy use, and so forth) all alone, without direction, pressure, or prompting from others. In such environments, learners who take part in SRL behaviors are much more inclined to be successful than learners who don't engage in SRL behaviors [26]. Alternatively, creating classroom learning environments that effectively engage students both experientially and cognitively have the potential of stimulating the development of self-regulated learning.

\section{Construction of Self-Regulated Language Teaching and Learning Environment}

As noted above, SRL involves cognitive, affective, motivational and behavioral components. Through the above fact, the author agree that self-regulation involves cognitive, affective, motivational and behavioral components that provide the individual with the capacity to adjust his or her actions and goals to achieve the desired results in light of changing environmental conditions [27]. In summary, SRL involves learning strategies and psychological processes that learners deliberately engage to help themselves learn and perform better academically. Teachers can provide the self-regulatory tools to discover what works best for the student themselves. For this reason, we believe that teachers are more effective when they function as models, consultants, and coaches, such as in an academy. Teachers can provide students with strategies and show them how to self-monitor their own learning processes accurately and accept the outcomes positively. Teachers are more effective when they construct a positive self-efficacy perspective about the power of self-regulated learning processes for each of their students.

Constructivist learning theory suggests that, in general, the language learning environment is composed of four elements of language environment, collaborative learning, conversation communication and meaning construction. "Language environment" refers to the teacher-led, for the students to construct an authentic language environment. The main content of instructional design to be considered is for students to create an appropriate "language environment", which plays an important role in constructivist learning theory, is a necessary prerequisite for the construction of meaning. Research on the relationship between classroom learning environment and SRL also shows that teachers should be through open, real situation tasks, establish a teaching environment highly characterized by self-regulated learning, to teach students in the field of strategic knowledge, demonstrate effective learning use strategies, organize materials and activities to support the use of strategies, and to provide 
effective support and practical opportunities through feedback, guidance and help students develop self-regulated learning skills and expertise [28]. Language teaching environment construction based on self-regulated learning strategies is very urgent, but to a certain extent, a high level of teachers' professional knowledge and teaching skills of its successful implementation is crucial.

A key trend in foreign language education has been the use of technology (online or web-based course) where the outcome variable was based on academic achievement. Studies involving solely traditional classroom learning, blended/hybrid learning environments, or used combined SRL strategies instead of single strategies were excluded. Technology is ideal for providing the extensive, repetitive practice required for successful mastery of foreign language. Learners are able to practice at their own particular pace, and to receive instant feedback on their performance. The self-regulated, individualized opportunities afforded by technology take a significant part of the drudgery inside and outside classroom-based practice and this feature appears to be particularly relevant to the adapting needs of learners. At the point the computer provides opportunities for learners to practice the language by doing spoken and written drills, completing comprehension questions, carrying out grammar exercises and so on, it is acting as an instructional tool. Technology in itself cannot transform classrooms; it is the pedagogical use of technology that can enhance teaching and learning. Thus, far reaching proficient advancement for technology ought to incorporate not only the development of mechanical information and skills, but also strategies for technology-enhanced teaching and learning, and for classroom management and practice. It should support teachers to comprehend the adjustments in teaching and learning process and the roles of teachers and students in the new technology-mediated learning environments.

As has been discussed, technology has the potential to provide language learners with essential environmental support in the learning process. If appropriately applied, it can offer multimedia platforms that stimulate language learners and encourage them to utilize their interest, develop their creativity and nurture their imagination to effectively explore the learning environment. Technology provides teachers with the opportunity to create classroom materials and tasks that are interactive, as well as allow variation in the pace, organization and decision-making in order to hold the attention of language learners. Similarly, technology can provide systematic schedules for learners to follow and to reinforce their learning through repetition of familiar activities. Finally, technology also meets the needs of language learners to feel a sense of achievement and satisfaction with their work by giving them instant feedback and summarizing their learning progress and effort. While these opportunities can be provided in other ways, few approaches allow all of them to be offered together. In sum, future research needs to place more emphasis not on "teaching how to teach" but on "teaching how to learn", as Holec proposed [29]. In terms of fostering self-regulated language teaching and learning, it would involve teachers to be receptive and observing, understanding and, if necessary, learn from their students. Besides, it is vital for teachers to realize the potential power of learner's self-regulation, to realize what is available, to support and exploit the conceivable outcomes, and to incorporate it into their learning environment. Language learning environments cannot be considered neutral. They tend to have either a repressive effect or the ability to strengthen learning and progressive initiatives to make change in society, so learning environments are not static or fixed.

\section{Conclusions and Implications}

How to cultivate and improve students' self-regulated learning ability inside and outside the actual foreign language classroom, in which teaching and learning of foreign language needs thorough and systematic research, and especially the construction of self-regulated environment needs to reveal what key learning classroom environment is characterized by, and how external teaching and guidance of teachers to students' conversion in the self-regulatory processes, and different subject content in self-regulated learning of training and training to the difference characteristics. However, behind the self-regulated learning and teaching strategies, there are some universal laws. Firstly, their functions and targets are located in influencing students' intrinsic motivation to enrich students' cognitive strategies, train students' meta-cognitive processes, and teach students to create a conducive learning environment, physical and social aspects; secondly, to emphasize student-centered teaching organization and put students in the dominant position of teaching process, as for teaching methods, this study advocates the learning style of self-study for students and to promote their inquiry-based learning, and gives full play to their enthusiasm, initiative and interest in learning. For the teaching procedure, the teacher should display the learning objectives to empower the students' learning motivation, guide them to self-study, group or collective discussions, the teachers concentrate on clarifying activities to consolidate and make the final evalua- 
tion and summary.

According to sociocultural theory, language plays a crucial role in gradual transition from joint problem solving to independent problem solving or self-regulation, where self-regulation implies strategic (i.e. meta-cognitive) control of the thinking processes needed to solve the problem. A central principle of the theory is that the interior language of thought developed by the learner to achieve this meta-cognitive control is internalised from the social-interactive discourse of joint problem solving with more capable others, during which various strategies and solutions are discussed and talked through. Moreover, with constructivist pedagogies, the circumstance is distinctive. Emphasis is obviously on students and on their learning processes. Since language learning is supposed to be a process of construction, constructivist pedagogies focus on the best way to organise learning environments which will support knowledge construction and language development. It is in this way not surprising that developers of innovation enhance learning environments and teachers who make these environments accessible to their students are much closer to the thoughts of constructivist pedagogies than to those of modern instructions. At the level of concrete learning environments, constructivist pedagogies advance themselves much better to the development of guidelines for their development than modern instructions. Thus, SRL, from a constructivist perspective, not only refers to the construction of knowledge and language development of students, but also to the observing of the corresponding development processes.

Whenever the factor learning environment is raised in the language learning study, it is presented as a means of regulating another form of control. Such results indicate that environmental control may not be a separate category of control in itself, but a self-regulatory mechanism or strategy to control other forms of regulation. In this capacity, the strategy of controlling one's learning environment is shown to have extremely positive effects on learners' self-regulation [30]. The new direction of foreign language teaching paradigm needs to create a learning environment framework suitable for life growth and development of the students, to construct a appropriate "language learning community", so that each student can adapt to their needs and personality education to meet their educational needs, physical needs, social needs, emotional needs, and the requirements of morality, and to seek harmonious development of each student's body and mind. As such a framework shapes, it should allow the results from a wide range of different studies to be plotted on an emerging general picture of various language learning environments. This study does not propose any one particular model and its evaluation method; rather it examines several dimensions or aspects of different types of language learning environment, ones which should enter into any useful future evaluation and practice. Much of what we propose will, no doubt, need modifying, but we believe that a framework resembling the one proposed will eventually be recognised as an essential element in the assessment and use of learning environments to help the students learn foreign language.

The relevant research on SRL theory shows that in the process of obtaining knowledge and skills, or in the formation process of personality, willpower, SRL for learner success is essential [31]. Therefore, the classroom, school and community should strengthen cooperation and jointly create efficient language teaching and learning environment, in which self-regulated teaching paradigm can be truly realized. Activities bring about improvements in classroom learning environments and enhance student affective and cognitive outcomes, which construct teacher quality and contribute to educational change processes, ought to be critical objectives for language teacher professional development. To better support teacher learning and build capacity for professional growth, teacher development activities ought to be systematic, classroom-based and supported by a constructivist methodology, which coordinates the center of teachers decisively on students and their learning. We hope that this study will encourage language teachers to integrate some technologies and concepts more fully into their teaching and will make them feel better prepared for the challenges ahead. Different learning environment models produce discernible differences in selecting which problems are faced, and these possibilities or obstacles can in turn be transformed and reconstructed. The concept of reflexive relations to one's environment helps us grasp this new dimension. In a fast-moving language learning environment, such as computer mediated learning, online learning, interactive learning, and web-based learning, etc, current models are never enough, thus this requires a major shift from transmissive toward more reflexive and transformative forms of language learning. Recognition of possible different reflexive relations to one's language learning environment, and therefore the potential of language learners' participation in it are critical to our new vision of foreign language education.

\section{Acknowledgements}

This paper was excerpted from a $\mathrm{PhD}$ thesis under the guidance of the College of International Studies at the 
Southwest University. A part of this research was funded with financial support from the Dali University Youth Staff Research Fund Program (2008X49).

\section{References}

[1] Guilloteaux, M.J. and Dörnyei, Z. (2008) Motivating Language Learners: A Classroom-Oriented Investigation of the Effects of Motivational Strategies on Student Motivation. TESOL Quarterly, 42, 55-77. http://dx.doi.org/10.1002/j.1545-7249.2008.tb00207.x

[2] Cheng, H. and Dörnyei, Z. (2007) The Use of Motivational Strategies in Language Instruction: The Case of EFL Teaching in Taiwan. Innovation in Language Learning and Teaching, 1, 153-174. http://dx.doi.org/10.2167/illt048.0

[3] Dörnyei, Z. and Csizer, K. (1998) Ten Commandments for Motivating Language Learners: Results of an Empirical Study. Language Teaching Research, 2, 203-229. http://dx.doi.org/10.1177/136216889800200303

[4] Guilloteaux, M.J. (2010) Caring Behaviors of Highly Motivating and Less Motivating Korean Teachers of English. The New Korea Association of English Language and Literature, 52, 329-354.

[5] Bembenutty, H. (2011) Self-Regulated Learning: New Directions for Teaching and Learning. John Wiley \& Sons, Hoboken.

[6] Zimmerman, B.J. (1990) Student Differences in Self-Regulated Learning. Journal of Educational Psychology, 82, 5159. http://dx.doi.org/10.1037/0022-0663.82.1.51

[7] Zimmerman, B.J. and Schunk, D.H. (2001) Self-Regulated Learning and Academic Achievement: Theoretical Perspectives. Lawrence Erlbaum Associates, Mahwah.

[8] Zimmerman, B.J. and Bonner, S. (1996) Developing Self-Regulated Learners: Beyond Achievement to Self-Efficiency. American Psychological Association. http://dx.doi.org/10.1037/10213-000

[9] Carneiro, R., Lefrere, P., Steffens, K. and Underwood, J. (2011) Self-Regulated Learning in Technology Enhanced Learning Environments: A European Perspective. Sense Publishers, Rotterdam. http://dx.doi.org/10.1007/978-94-6091-654-0

[10] Su, D., Fang, P. and Song, J. (2011) A Review and Perspective of the Study of Self-Regulated Learning. Journal of Tianjin Normal University (Social Science), 2, 77-79.

[11] Zimmerman, B.J. (2000) Attainment of Self-Regulation: A Social Cognitive Perspective. In: Boekaerts, M., Pintrich, P.R. and Zeidner, M., Eds., Handbook of Self-Regulation, Academic Press, San Diego, 13-39. http://dx.doi.org/10.1016/B978-012109890-2/50031-7

[12] Winne, P.H. and Perry, N.E. (2000) Measuring Self-Regulated Learning. In: Boekaerts, M., Pintrich, P.R. and Zeidner, M., Eds., Handbook of Self-Regulation, Academic Press, San Diego, 531-566. http://dx.doi.org/10.1016/b978-012109890-2/50045-7

[13] Zimmerman, B.J. and Tsikalas, K.E. (2005) Can Computer-Based Learning Environments (CBLEs) Be Used as Self-Regulatory Tools to Enhance Learning? Educational Psychologist, 40, 267-271. http://dx.doi.org/10.1207/s15326985ep4004_8

[14] Steffens, K. (2006) Self-Regulated Learning in Technology Enhanced Learning Environments: Lessons of a European Peer Review. European Journal of Education, 41, 397-414. http://dx.doi.org/10.1111/j.1465-3435.2006.00271.x

[15] Hilden, K.R. and Pressley, M. (2007) Self-Regulated through Transactional Strategies Instruction. Reading and Writing Quarterly, 23, 51-75. http://dx.doi.org/10.1080/10573560600837651

[16] Fullan, M. (1993) Change Forces: Probing the Depths of Educational Change. Teachers College Press, New York.

[17] Wiśniewska, D. (2013) Interest and Interest-Enhancing Strategies of Adolescent EFL Learners. ELT Journal, 67, 210219. http://dx.doi.org/10.1093/elt/ccs079

[18] Fraser, B.J. (2007) Classroom Learning Environments. In: Abell, S.K. and Lederman, N.G., Eds., Handbook of Research on Science Education, Lawrence Erlbaum, Mahwah, 103-124.

[19] Fraser, B.J. (2012) Classroom Learning Environments: Retrospect, Context And Prospect. In: Fraser, B.J., Tobin, K.G. and McRobbie, C.J., Eds., The Second International Handbook of Science Education, Springer, Dordrecht, 1191-1239. http://dx.doi.org/10.1007/978-1-4020-9041-7_79

[20] Hamilton, R. and Ghatala, E. (1994) Learning and Instruction. McGraw-Hill, New York.

[21] De Corte, E., Verschaffel, L., Entwistle, N. and van Marriënboer, J. (2003) Powerful Learning Environment: Unravelling Basic Components and Dimensions. Elsevier Science Ltd., Oxford.

[22] Chen, C. and Li, Y. (2010) Personalised Context-Aware Ubiquitous Learning System for Supporting Effective English Vocabulary Learning. Interactive Learning Environments, 18, 341-364. http://dx.doi.org/10.1080/10494820802602329

[23] Wang, Q. (2009) Designing a Web-Based Constructivist Learning Environment. Interactive Learning Environments, 
17, 1-13. http://dx.doi.org/10.1080/10494820701424577

[24] Carneiro, R., Lefrere, P., Steffens, K. and Underwood, J. (2011) Self-Regulated Learning in Technology Enhanced Learning Environments. Sense Publishers, Rotterdam. http://dx.doi.org/10.1007/978-94-6091-654-0

[25] United Nations Educational Scientific and Cultural Organisation (UNESCO) (2012) A Place to Learn: Lessons from Research on Learning Environments. UNESCO Institute for Statistics, Montreal.

[26] Schunk, D.H. (2004) Learning Theories: An Educational Perspective. 4th Edition, Merrill \& Prentice Hall, Upper Saddle River.

[27] Zeidner, M., Boekaerts, M. and Pintrich, P. (2000) Self-Regulation. Directions and Challenges for Future Research. In: Boekaerts, M., Pintrich, P. and Zeidner, M., Eds., Handbook of Self-Regulation, Academic Press, New York, 749-768. http://dx.doi.org/10.1016/b978-012109890-2/50052-4

[28] Zimmerman, B.J. and Schunk, D.H. (2011) Handbook of Self-Regulation of Learning and Performance. Routledge Press, New York.

[29] Holec, H. (1981) Autonomy and Foreign Language Learning. Pergamon Press, Oxford.

[30] Rose, H. and Harbon, L. (2013) Self-Regulation in Second Language Learning: An Investigation of the Kanji-Learning Task. Foreign Language Annals, 46, 96-107. http://dx.doi.org/10.1111/flan.12011

[31] Boekaerts, M. and Niemivirta, M. (2000) Self-Regulated Learning: Finding a Balance between Learning Goals and Ego-Protective Goals. In: Boekaerts, M., Pintrich, P.R. and Zeidner, M., Eds., Handbook of Self-Regulation, Academic Press, San Diego, 417-450. http://dx.doi.org/10.1016/b978-012109890-2/50042-1 